\title{
ANNUAL ASSESSMENT OF HIGHWAY TRAFFIC NOISE USING TWO CHANNEL SHORT-TERM MEASUREMENTS
}

\author{
Aleksandras Jagniatinskis ${ }^{1}$, Boris Fiks ${ }^{2}$, Delia Dimitriu ${ }^{3}$ \\ ${ }^{1,2}$ Scientific Institute of Thermal Insulation, Vilnius Gediminas Technical University, Lithuania \\ ${ }^{3}$ Centre for Air Transport and the Environment, Manchester Metropolitan University, United Kingdom
}

Submitted 16 October 2013; resubmitted 3 December 2013; accepted 3 March 2014

\begin{abstract}
Research has shown that for residential area nearby (up to $50 \mathrm{~m}$ ) exurbia roads, there are cases where the evaluation of noise impact needs more than using the calculation methods alone. Thus, in order to confirm (or not) the implementation of designed measures for noise abatement procedures in these areas, some direct acoustical measurements of traffic flow are required. The present paper deals with the development of new approach to the methodology that allows truly estimate the annual $L_{d e n}$ value using the one short-term (till $1 \mathrm{~h}$ ) time interval measurement. The method is based on the original extrapolation procedure that allows to adapt results obtained in representative shortterm time interval to the annual average rating time periods of day $(12 \mathrm{~h})$, evening $(4 \mathrm{~h})$ and night $(8 \mathrm{~h})$, for which the $L_{d e n}$ value is assessed. The procedure is based on the statistical processing of Sound Exposure Levels (SEL) distribution histogram of all vehicles passing by and registered on the reference microphone. The sound propagation correction is evaluated by applying simultaneous measured sound levels registration on two microphones, placed in reference point and in receiver point, considering living environment. This method allows to extend results of extrapolation obtained in the reference point into desired environment point, where such extrapolation to the annual noise levels can not be done.
\end{abstract}

Keywords: road transport; noise; measurements; sound exposure; statistical assessment; annual descriptors.

Reference to this paper should be made as follows: Jagniatinskis, A.; Fiks, B.; Dimitriu, D. 2014. Annual assessment of highway traffic noise using two channel short-term measurements, Transport 29(2): 204-211.

http://dx.doi.org/10.3846/16484142.2014.931295

\section{Introduction}

Noise in the areas near the exurbia roads and highways is mainly produced by road traffic flow. The EC noise directive (Directive 2002/49/EC 2002) introduces the mandatory noise descriptor $L_{d e n}$ for noise pollution evaluation. This annual average descriptor depends on the annual average day $L_{d}$, evening $L_{e}$ and night $L_{n}$ equivalent sound pressure levels and for the Lithuanian case (Lietuvos Respublikos triukšmo... 2004), it may be expressed as follows:

$$
L_{d e n}=10 \cdot \lg \left(0.5 \cdot 10^{\frac{L_{d}}{10}}+0.527 \cdot 10^{\frac{L_{e}}{10}}+3.33 \cdot 10^{\frac{L_{n}}{10}}\right) \text {. }
$$

So, the contribution of night level is most significant, but the contributions from day and evening levels are the same. Thus, noise for pollution assessment purposes must evaluate the annual values of $L_{d}, L_{e}$ and $L_{n}$. Generally, this is done by calculation methods used in noise mapping for the areas near the roads. In these commercial (Bendtsen 1999; Steele 2001; Pamanikabud, Tansatcha 2003) and new developed (Cho et al. 2004; King, Rice 2009; Hamet et al. 2010) methods the possible realizations of noise mapping calculations are described. This may be presented as follows:

$$
L_{e q, T}=L_{r e f}+C_{r e c}+C_{r o a d}
$$

where: $L_{e q, T}$ is the evaluated noise level for time interval $T$ (day, evening or night); $L_{r e f}$ is the calculated level at reference (initial for further calculations) point (normally from $7.5 \mathrm{~m}$ to $15 \mathrm{~m}$ from road centre line at $4 \mathrm{~m}$ height); $C_{r e c}$ is the correction due to receiver point position or environmental sound propagation correction (i.e. receiver distance from noise source, ground attenuation, screening, reflections are taken into account); $C_{\text {road }}$ is the correction taking into account parameters that characterise a road itself (gradient, surface type and quality).

In addition, the correction due to weather conditions may be considered as it is described in Lithuanian Standard (LST ISO 1996-2:2008). 
The initial data for $L_{\text {ref }}$ calculation are the annually averaged one whole-day (by hours) traffic flow data (every vehicle category amount and speed) and Sound Exposure Levels (SEL) database, for all considered transport categories depending on the speed values.

However, there are cases for residential areas nearby (till $50 \mathrm{~m}$ ) the roads where additionally the direct acoustical measurements of traffic flow are required to confirm or not the implementation of designed measures (noise barriers construction, building façade sound insulation improvement, speed limiting, etc.) for noise abatement in these areas.

Generally annual $L_{d e n}$ assessment as shown in (Gaja et al. 2003) may be accomplished using a sampling technique that results in few randomly chosen whole-days noise monitoring measurements. In (Ng, Tang 2008) was shown that one day $L_{d e n}$ assessment may be done using arbitrarily chosen few representative short-term measurement periods. The possibility to reduce common measurement time for assessment the annual level $L_{d e n}$ based on the partially deterministic model for choosing the number of successive representative measurement days is considered in (Jagniatinskis, Fiks 2014). The best results obtained were for representative one-week continuous measurements giving an uncertainty for annual $L_{d e n}$ of about $2 \mathrm{~dB}$.

Near exurbia roads, the overall noise is not stable and time-history comprises individual vehicle passing by events as shown in Fig. 1 .

In this case, there is a possibility to perform the annual $L_{d e n}$ assessment by permanent measurements in representative short-term period and not exceeding $1 \mathrm{~h}$. Such assumption is based on the following:

- annual average (hourly for one whole-day) traffic flow data (amount of considered vehicle categories and speed) to be available;

- measurement time period may be chosen, so that will include enough amount of considered vehicle categories passing by to meet the statistically representative time interval sample required by the measurement accuracy (LST ISO 1996-2:2008); also, the conformity to average traffic parameters on the considered road in chosen measurement time interval is required;

- for exurbia roads applying the traffic registration methods (video recording; traffic flow measuring equipment, e.g. 'TRAX Flex' or method presented by Mato-Méndez and Sobreira-Seoane (2011), etc.) it is possible to identify the most significant vehicle passing by (that is valid for Lithuanian case, where traffic flows are mostly not steady). That allows to recognize the sound level time history of these passing by (see Fig. 1 as example) and determine the corresponding SEL;

- when these SEL's values are determined in the immediate vicinity of the road (e.g. $7.5 \div 15 \mathrm{~m}$ from road centre line - reference measurement point), they may be considered as the basic data that characterize the initial sound energy produced by vehicle passing by;

- it is a possibility that in the reference point to calculate the equivalent sound pressure level $L_{r e f}$ for chosen measurement time interval using calculated SEL values;

- by provisions of standard (LST ISO 1996-2:2008), the results of equivalent level determined in the representative time interval may be extrapolated into rating time intervals day ( $12 \mathrm{~h}$ from $06: 00$ to 18:00) $-L_{d}$, evening ( $4 \mathrm{~h}$ from 18:00 to 22:00) $L_{e}$ and night ( $8 \mathrm{~h}$ from 22:00 to $\left.06: 00\right)-L_{n}$, and this as was shown to may be done by statistical processing of calculated SEL values, based on the fact that vehicle passing by events do not depend on the time of the day;

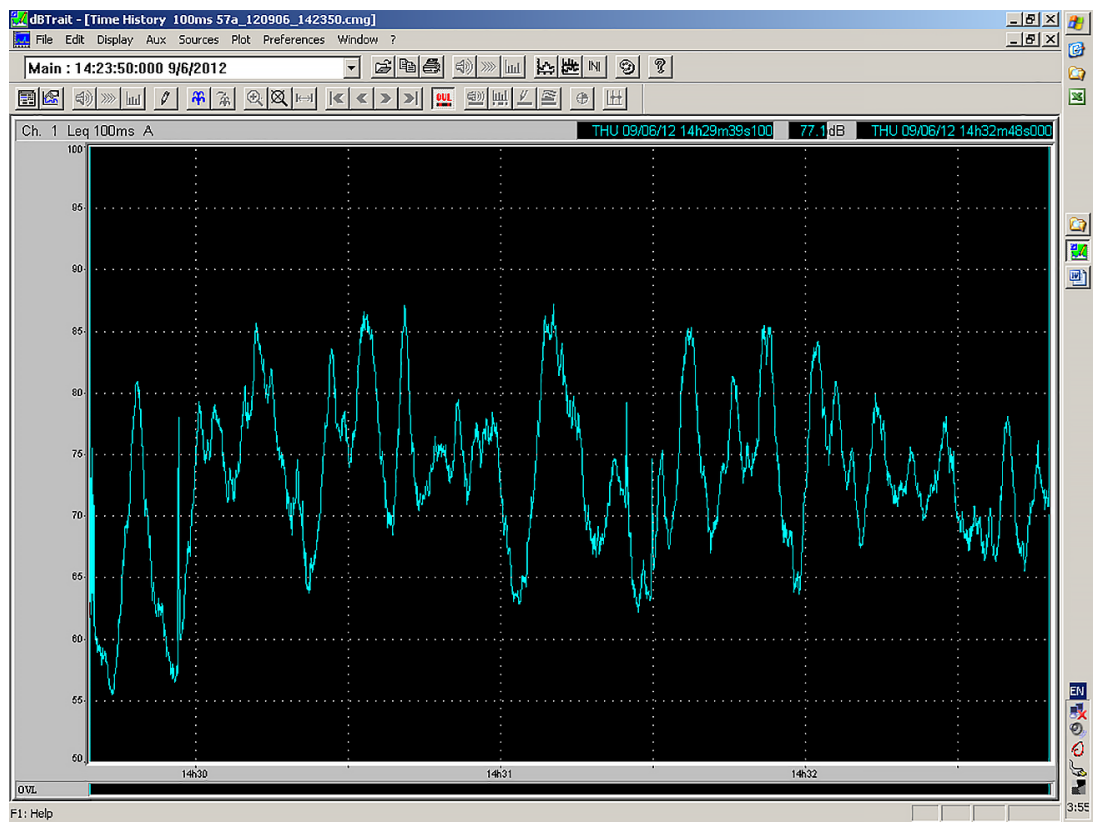

Fig. 1. The typical sound level time-history at reference microphone in short-term measurement time interval 
- the 'receiver' correction $C_{r e c}$ may be evaluated using the results of simultaneous direct equivalent level measurements on two microphones placed in the reference and receiver points;

- the 'road' correction $C_{\text {road }}$ is included in the sound level time history of every vehicle passing by.

Thus, all parameters presented in formulas (1) and (2) may be determined.

\section{Acquisition of Initial Data}

The basic data were obtained using a two-channel sound level meter 'Symphonie $01 \mathrm{~dB}$-Stell' with a two free field microphones G.R.A.S. to accomplish the produced sound by traffic flow sound time history registrations on two microphones simultaneously (see Fig. 1 as example).

To collect noise emission data the reference point microphone is located in the immediate vicinity of the road at the distance from the centre-line of a road from $7.5 \mathrm{~m}$ to $15 \mathrm{~m}$, while the receiver point microphone is located in the considered investigated site where the annual $L_{d e n}$ value has to be evaluated. The height of both microphones above the ground surface level may be of $4 \mathrm{~m}$ or $1.5 \mathrm{~m}$, depending on the aim of the measurements. The sound time history of traffic flow in the chosen representative time interval is registered on both microphones simultaneously, as the two discreet sets of instantaneous A-weighted sound pressure levels $L_{p A, 100 \mathrm{~ms}}$. Therefore, the time-domain $100 \mathrm{~ms}$ sampling is applied. Correspondingly, a non-sound traffic flow data were registered at the same time: category of vehicle (in Lithuania the only light and heavy categories of vehicle are considered), as well as their speed. The weather conditions are also controlled by the weather station 'Kestrel 4500 ', to correspond to normal conditions, as it is stated in standard (LST ISO 1996-2:2008).

Therefore, for the assessment of annual $L_{d e n}$ value following parameters must be directly measured (determined), obtained and calculated:

- directly measured equivalent continuous Aweighted sound pressure levels at reference point $\left(L_{\text {Aeq,T,ref }}\right)$ and at receiver point $\left(L_{\text {Aeq, }, \text { rec }}\right)$ in chosen measurement representative time interval $T=T_{\text {repr }}$

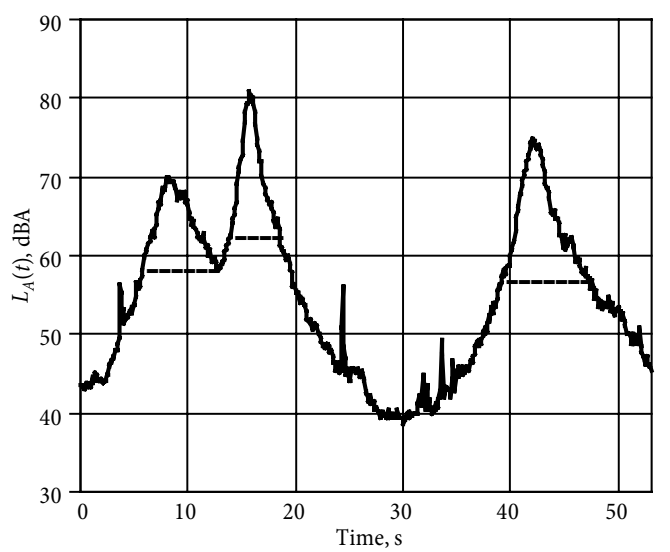

Fig. 2. Example of records of three vehicle passing by (dashed lines show the intervals of $t_{E}$ )
- directly determined traffic flow data in time interval $T$ : the number and average velocity of passing by heavy transport/vehicles, $N_{T, \text { heavy }}$ and $V_{T, \text { heavy }}$ respectively; the number and average velocity of passing by light transport/vehicles, $N_{T, \text { light }}$ and $V_{T, \text { light }}$ respectively;

- declared by road department the hourly one whole-day annual average number of heavy $N_{h, \text { heavy }}$ and light $N_{h, \text { light }}$ transport and also annual average speed $V_{Y \text {, heavy }}$ and $V_{Y, \text { light }}$ for heavy and light transport respectively;

- the set of A-weighted SEL, $L_{A E, i}(i=1, \ldots, N$, where $N$ is the number of all passing by vehicles) of every vehicle passing by, determined by calculations from the recorded time history of instantaneous A-weighted sound pressure levels $L_{p A, 100 m s}$ acquired at reference microphone point.

From the above presented parameters, the only SEL data are obtained, by using specially developed software. This software allows to recognize every vehicle passing by event (see Fig. 2 as example of three events) and calculate the individual event $L_{A E}$ (SEL) value applying the common formula:

$$
L_{A E}=10 \cdot \lg \left(\frac{1}{\tau_{r e f}} \cdot \int_{0}^{t_{E}} 10 \frac{L_{A}(t)}{10} d t\right),
$$

where: $L_{A}(t)$ is a separated individual passing by time history of $L_{p A, 100 m s}$ values (dBA); $t_{E}$ is a corresponding separated time interval (s) and $\tau_{r e f}=1 \mathrm{~s}$.

After the SEL value for every vehicle passing by event are determined using formula (3), they are grouped with a step of $1 \mathrm{~dB}$ to build a corresponding histogram of SEL distribution densities like analogously was done (Jagniatinskis et al. 2011).

So, it helps to get an initial measured histogram $\left(h_{k}=n_{k} / N, k=1, \ldots, J\right)$, where: $n_{k}$ is the amount of $L_{A E, i}$ (SEL) values falling into $k$-th interval (or the number of vehicle passing by, whose exposure level $L_{A E, i}$ lies in interval $\left.L_{\mathrm{AE}, k} \pm 0.5 \mathrm{~dB}\right)$ and $N=N_{\text {light }}+N_{\text {heavy. }}$. In this histogram $H^{*} \%\left(H^{*}=N_{\text {heavy }} / N\right)$ of all $100 \%$ SEL values belong to the heavy vehicle. This paper proposes that SEL values of heavy transport are greater than SEL values of light transport. Thus, exist one of SEL values

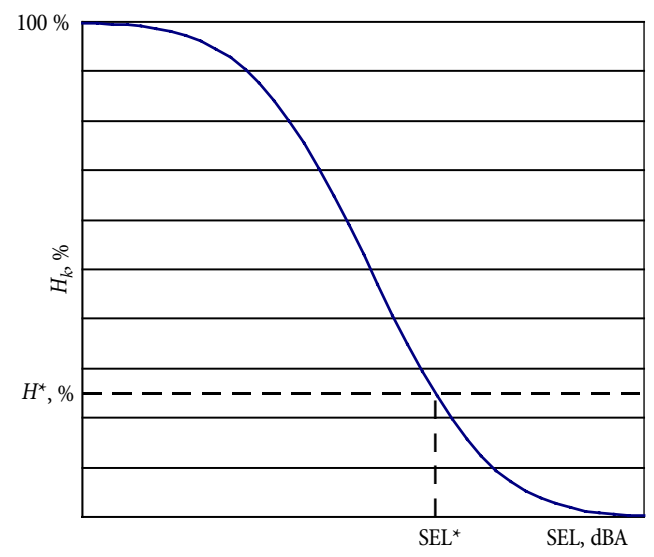

Fig. 3. Definition of SEL* value that separates SEL's of light and heavy vehicle passing by $\left(H^{\star}-\right.$ proportion of heavy vehicle) 
(denoted as SEL ${ }^{*}$ that separates SEL values of light and heavy vehicle in histogram. This SEL may be determined from the cumulative function $\left(H_{k}=1-\sum_{m=1}^{k} h_{m}\right.$, $k=1, \ldots, J)$ of measured histogram as shown in Fig. 3. Index of $k$ that corresponds to this $\mathrm{SEL}^{*}$ value is denoted as $k^{\star}$.

\section{Algorithm for Annual $L_{d e n}$ Determination}

The below presented procedure describes the order of operation for annual composite descriptor $L_{\text {den }}$ determination at the receiver point in the investigated residential site (the appropriate block-diagram is presented in Fig. 4):

1) Simultaneous direct using of two microphones acoustic measurements at the reference and receiver points and non acoustic traffic flow data registration (measurements) in time interval $T=T_{\text {repr }}$ seem to be too large to be representative. The time history of instantaneous $L_{p A, 100 m s}$ in the reference and receiver points data storage.

2) Calculation from registered traffic flow data (video or/and obtained with special instrumentation) the number of light $N_{T, \text { light }}$ and heavy $N_{T, \text { heavy }}$ transport and there speed evaluation.

3) Checking for data to be a representative. In this $T_{\text {repr }}$ time interval the number of passing by heavy and light vehicle must fulfil the measurement accuracy requirement of standard (LST ISO 1996-2:2008) and the proportion of heavy and light vehicle must be similar, if possible, to declared annual average proportion of these vehicle categories for the day-time when measurements are carried out.

4) Direct calculation from measurement results the equivalent continuous levels in representative time interval at both reference and receiver points $L_{\text {Aeq, } T_{\text {repr }}, \text { ref }}$ and $L_{\text {Aeq, } T_{\text {repr }}, \text { rec }}$. The 'receiver' (environmental sound propagation) correction $C_{r e c}$ is determined by using the formula:

$$
C_{\text {rec }}=L_{\text {Aeq, }, T_{\text {repr }}, \text { ref }}-L_{\text {Aeq, }, T_{\text {repr }}, \text { rec }} \text {. }
$$

5) Sound exposure level $L_{A E, i}(i=1, \ldots, N)$ of every vehicle passing by determination at the reference point using the discrete form of formula (3):

$$
L_{A E, i}=10 \cdot \lg \left(\frac{t_{i}}{n(i) \cdot \tau_{r e f}} \sum_{j=1}^{n(i)} 10^{0.1 \cdot L_{A, i, j}}\right),
$$

where: $t_{i}$ is time duration in seconds of the most significant part (usually area of event until the sound pressure level has failed at least $10 \mathrm{~dB}$ below the maximum level of event) of $i$-th event (while $\tau_{\text {ref }}=1 \mathrm{~s}$ ); $L_{A, i, j}$ is the time history of instantaneous A-weighted sound pressure levels $L_{p A, 100 m s}$ of $i$-th vehicle passing by event (so, $t_{i}=100 \cdot(n(i)-1)[\mathrm{ms}]$ and $n(i)$ is a number of samples of $i$-th event) acquired at the reference microphone point. Thus, the appropriate histogram $\left(h_{k}, k=1, \ldots, J\right)$ for SEL $\left(L_{A E, i}\right)$ values may be built as described in Section 1.

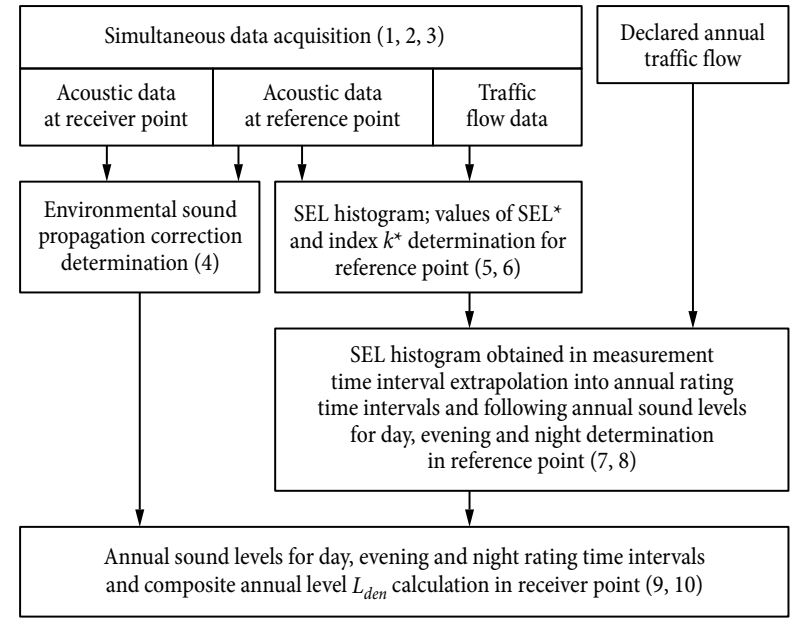

Fig. 4. Block diagram of algorithm for annual $L_{d e n}$ determination (number in brackets presents the number of operation step in described procedure)

6) Determination of SEL* value and an appropriate index $k^{\star}$ that separates SEL's of light and heavy vehicle passing by from cumulative function of obtained representative histogram and measured proportion of heavy vehicle $H^{\star}$ as described in Section 1 (see Fig. 3).

7) Extrapolation of SEL histogram obtained in representative measurement time interval $T_{r e p r}$ at reference point for rating time intervals: day $(12 \mathrm{~h}$, from 06:00 to 18:00), evening ( $4 \mathrm{~h}$, from 18:00 to 22:00) and night ( $8 \mathrm{~h}$ : from 22:00 to 06:00). This is done by calculating the set of coefficients $\left(R_{T, c a t}\right.$, where $T$ denote the rating time interval (day, evening or night) and index 'cat' denote the category of vehicle (light or heavy)) corresponding to declared annual average traffic flow parameters in rating time intervals. The procedure for determination of these coefficients is presented further, in Section 3.

8) Determination of annual average levels $L_{d, r e p} L_{e, \text { ref }}$ $L_{n, \text { ref }}$ for day, evening and night rating time intervals at reference point as an equivalent continuous sound pressure level $L_{\text {Aeq,T } T}$ in rating time interval $T$ for appropriate whole-day periods from formula:

$$
\begin{aligned}
& L_{\text {Aeq,T }}=10 \cdot \lg \left(R_{T, \text { light }} \cdot \sum_{k=1}^{k^{*}-1} h_{k} \cdot 10^{0.1 \cdot L_{A E, k}}+\right. \\
& \left.R_{T, \text { heavy }} \cdot \sum_{k=k^{\star}}^{J} h_{k} \cdot 10^{0.1 \cdot L_{A E, k}}\right)+10 \cdot \lg \left(\frac{\tau_{r e f}}{T} \cdot N_{T}\right),
\end{aligned}
$$

where: $N_{T}$ is a declared number of light and heavy vehicle passing by in rating time interval $T$ (day, evening or night).

This formula is derived from the common formula presented by Jagniatinskis and Fiks (2012), which describes the relationship between the values of SEL's histogram obtained in representative (measurement) time interval $T_{\text {repr }}$ and corresponding equivalent level:

$L_{\text {Aeq, }, T}=10 \cdot \lg \left(\frac{\tau_{r e f}}{T_{r e p r}} \cdot N_{r e p r} \cdot \sum_{k=1}^{J}\left(h_{k} \cdot 10^{0.1 \cdot L_{A E, k}}\right)\right)$, 
where: $N_{\text {repr }}$ is a number of light and heavy vehicle passing by in representative (measurement) time interval $T_{\text {repr }}$.

9) Determination of annual average levels $L_{d}, L_{e}, L_{n}$ for day, evening and night rating time intervals at receiver point of investigated living environment from formula:

$$
L_{d(e, n)}=L_{d(e, n), r e f}-C_{r e c} .
$$

10) Determination of desired composite annual level $L_{\text {den }}$ using formula (1).

\section{Determination of Coefficients for Extrapolation}

Separately for every rating time interval $T$, two coefficients $R_{T \text {, light }}$ and $R_{T \text {, heavy }}$ need to be determined. They are applied to recalculate the representative SEL's histogram, which is obtained from measurements data in representative time interval into another rating time interval with corresponding proportion of light and heavy vehicle. If proportion of light and heavy vehicle in any rating time interval is the same as in representative time interval, the representative histogram is applied to this rating time interval and coefficients $R_{T, \text { light }}$ and $R_{T \text {, heavy }}$ are equal to 1 . Otherwise, these coefficients must be determined in the following manner: formally, as follows from Fig. 3 index $k^{\star}$ for which corresponds the SEL ${ }^{\star}$ value that separates SEL's of light and heavy vehicle passing by events may be determined from cumulative function of histogram using formula:

$$
k^{\star}=\max _{k \in\{1 \div J-1\}}\left(\sum_{m=J-k-1}^{J} h_{m} \leq H^{\star}\right)
$$

where: $H^{*}$ is measured proportion of heavy vehicle for representative time interval.

So $k^{\star}$ is the highest of $k$ values when the condition in the figure brackets is fulfilled. In addition, this is enough to deal with heavy vehicle statistics. So, if for any rating time interval the declared proportion of heavy vehicle is $H_{d} \neq H^{\star}$ and the part of histogram belonging to heavy transport is denoted as $H_{\text {heavy }}=\sum_{k=k^{*}}^{J} h_{k}$, to accomplish extrapolation of obtained representative histogram to any rating time interval the value of $H_{\text {heavy }}$, it is necessary to be changed proportionally to the proportion $H_{d} / H^{\star}$. Then, such percentage increment $\Delta$ [\%] for part of extrapolated histogram belonging to heavy transport is:

$$
\Delta=\left(1-\frac{H_{d}}{H^{*}}\right) \cdot H_{\text {heavy }} .
$$

This increment $\Delta[\%]$ must be proportionally distributed between all components of extrapolated histogram, so that the part of histogram belonging to heavy transport is 'reduced' by the value of $\Delta[\%]$ and on this value part of histogram belonging to light transport is 'increased'. So the part of histogram belonging to light transport denoted as $H_{\text {light }}=\sum_{k=1}^{k^{\star}-1} h_{k}$. Then, for heavy and light transport the following equations must be fulfilled, in order to determine the coefficients for histogram extrapolation to rating time interval $T, R_{T \text {,heavy }}$ and $R_{T, \text { light }}$

$$
\begin{aligned}
& H_{\text {heavy }}-R_{\text {T,heavy }} \cdot H_{\text {heavy }}=\Delta ; \\
& H_{\text {light }} \cdot R_{\text {T,light }}-H_{\text {light }}=\Delta .
\end{aligned}
$$

The finally extrapolated histogram components are found by multiplying the measured representative histogram components $h_{k}$ by the coefficients $R_{T, \text { heavy }}$ and $R_{\text {T, light }}$.

\section{Experimental Results}

The related measurements were carried out on the 6 September 2012 on the $57 \mathrm{~km}$ arterial highway No A5 Kaunas-Marijampole. The measurement site scheme is presented in Fig. 5.

The reference microphone (point 1) was placed at $15 \mathrm{~m}$ distance from centre line of arterial road (two-line in both directions) at height of $4 \mathrm{~m}$ above ground level. The receiver microphone (point 2) was placed at $36 \mathrm{~m}$ distance from road centre line at height of $4 \mathrm{~m}$ above ground level. Both microphones were placed in the free acoustic sound field.

The permissible vehicle speed on this road is $90 \mathrm{~km} / \mathrm{h}$. Measured from two microphones sound indicator data were simultaneously collected in one hour interval from 13:45 to $14: 45$. During this time, the interval three separate short-term measurements were restarted newly: from 13:45 to 14:00, from 14:00 to $14: 25$ and from $14: 25$ to $14: 45$. In order to estimate the accuracy of the measurement, these three measurements were performed under repeatability conditions when the measurement time interval was changing as $15 \mathrm{~min}$,

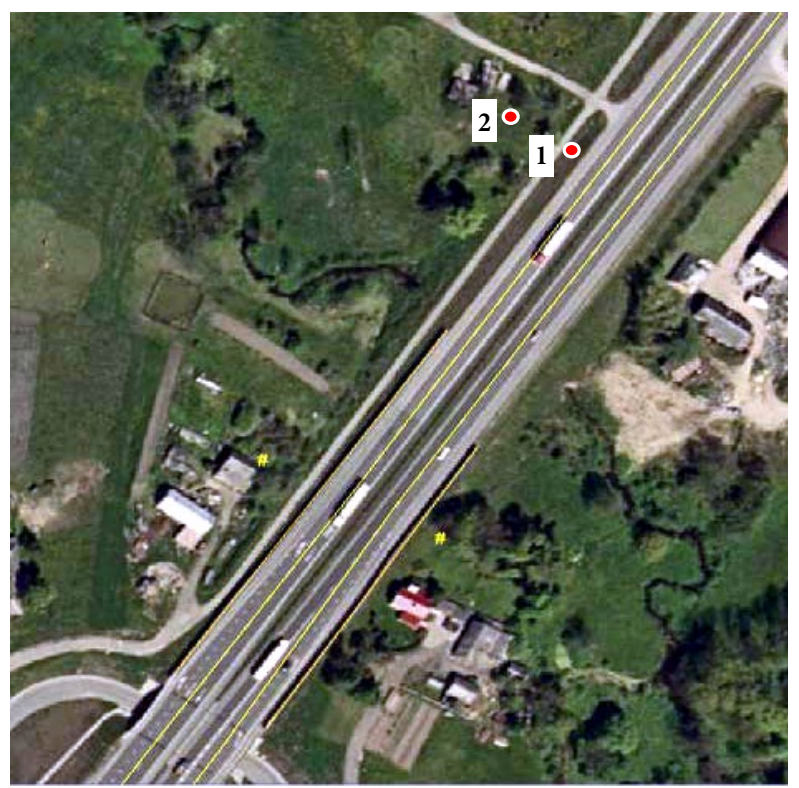

Fig. 5. The measurement site scheme: point 1 - reference microphone; point 2 - microphone for noise assessment at the environment site 
$25 \mathrm{~min}$, and $20 \mathrm{~min}$. The traffic flow parameters on the considered road section for the year 2011 and the flow data registered are presented in Tables 1 and 2.

The presented data in Table 2 show that they correspond to the average data of the year 2011 and may be considered as a representative sample of the annual data. The number of heavy transport passing by in all considered measurement time periods is much larger than 30, which satisfies the requirements of (LST ISO 1996-2:2008), as described in Section 1. Additionally, as shown in Tables 1 and 2, the percentage values of heavy transport in measurement time intervals fully correspond to the declared annual average percentage for considerated periods. Thus, the collected measurement data may be considered as representative and the algorithm for these data extrapolation to the rating time periods may be applied.

Firstly, the assessment of the environmental sound propagation correction using formula (4) was performed. The results are presented in Table 3.

Next step represents the post processing of all recorded levels using the algorithm presented in Section 2 (step 5) to determinate the SEL for all detected passing by events in three chosen measurement time intervals. So, the appropriate three distribution histograms for every time interval may be obtained as described in Section 1. Determination of $\mathrm{SEL}^{*}$ value and an appropriate index $k^{\star}$ from cumulative function for each of three representative histograms are presented in Fig. 6, using the measured proportion of heavy vehicle $H^{\star}$ (see Table 2).

Table 1. The declared annual average light and heavy $\left(H_{d}\right)$ transport data on traffic flow on the considered road section for the year 2011

\begin{tabular}{cccc}
\hline $\begin{array}{c}\text { Rating time } \\
\text { interval }\end{array}$ & Total, $N_{T}$ & Light [\%] & $\begin{array}{c}\text { Heavy, } \\
H_{d}[\%]\end{array}$ \\
\hline 06:00 - 18:00 h & 11505 & 65.3 & 34.7 \\
\hline 18:00 - 22:00 h & 2487 & 74.2 & 25.8 \\
\hline 22:00 - 06:00 h & 1121 & 59.2 & 40.8 \\
\hline 13:00 - 14:00 h & 1068 & 64.1 & 35.9 \\
\hline 14:00 - 15:00 h & 1074 & 64.8 & 35.2 \\
\hline
\end{tabular}

Table 2. Directly recorded light and heavy $\left(H^{*}\right)$ transport data during the period of noise measurements

\begin{tabular}{cccc}
\hline $\begin{array}{c}\text { Interval of } \\
\text { measurements }\end{array}$ & Total & Light [\%] & Heavy, $H^{\star}[\%]$ \\
\hline 1) 13:45 - 14:00 h & 290 & 66.2 & 33.8 \\
\hline 2) 14:00 - 14:25 h & 482 & 65.9 & 34.1 \\
\hline 3) 14:25 - 14:45 h & 385 & 66.7 & 33.3 \\
\hline
\end{tabular}

Table 3. Directly measured levels, dBA and sound propagation correction, $\mathrm{dB}$

\begin{tabular}{cccc}
\hline $\begin{array}{c}\text { Measurement } \\
\text { interval }\end{array}$ & $\begin{array}{c}\text { Reference } \\
\text { point 1 }\end{array}$ & $\begin{array}{c}\text { Receiver } \\
\text { point 2 }\end{array}$ & $\begin{array}{c}\text { Correction, } \\
C_{r e c}\end{array}$ \\
\hline 1 & 78.1 & 69.6 & 8.5 \\
\hline 2 & 78.4 & 69.7 & 8.7 \\
\hline 3 & 77.8 & 69.5 & 8.3 \\
\hline
\end{tabular}

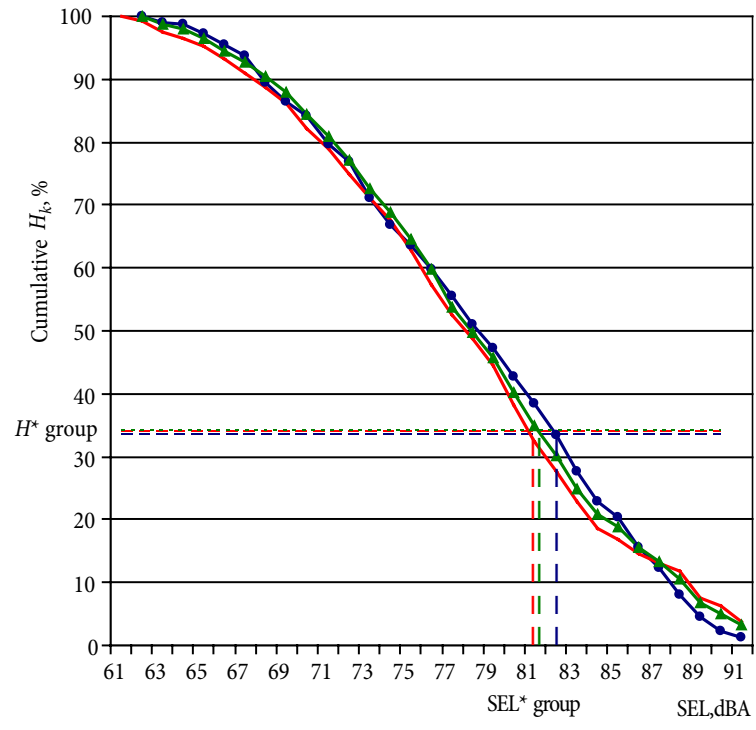

Fig. 6. Obtained cumulative functions for definition of $\mathrm{SEL}^{*}$ values for three chosen time intervals: interval $1-$ red $\left(\mathrm{SEL}^{\star}=81\right) ; 2-$ green $\left(\mathrm{SEL}^{*}=81\right)$ and 3 - blue $\left(\mathrm{SEL}^{*}=82\right)$; $H^{\star}$ group denote proportions of heavy vehicle for three time intervals (Table 2)

For every considered three time intervals, three desired indexes of $k^{\star}$, that separate in SEL's histograms SEL values of light transport from SEL values of heavy transport, may be found from Fig. 6. So $k^{*}$ values for histograms in the first and third time intervals are equal to 21 and for the second one - is equal to 20 (the histograms for time intervals 2 and 3 start from $62 \mathrm{dBA}$, while histogram for time interval 1 starts from $61 \mathrm{dBA}$ ).

Consequently, the extrapolation procedure as described in Section 3 may be carried out. From formula (10), the percentage increment $\Delta \%$ that presents the heavy transport percentage changing in rating time periods $T$ in comparison with the heavy transport percentage in measurement representative time intervals, as well the coefficients $R_{T, \text { heavy }}$ and $R_{T, \text { light }}$ in formulas (11) and (12), may be calculated. The results are presented in Table 4.

Table 4. Values of parameters in formulas (10)-(12) which are necessary for measured histogram extrapolation to the rating time periods

\begin{tabular}{ccccc}
\hline \multirow{2}{*}{$\begin{array}{c}\text { Measured } \\
\text { interval No }\end{array}$} & Parameter & \multicolumn{3}{c}{ Rating time period } \\
\cline { 2 - 5 }$(12 \mathrm{~h})$ & $\begin{array}{c}\text { Evening } \\
(4 \mathrm{~h})\end{array}$ & $\begin{array}{c}\text { Night } \\
(8 \mathrm{~h})\end{array}$ \\
\hline \multirow{3}{*}{1} & $\Delta[\%]$ & -0.86 & 7.67 & -6.71 \\
\cline { 2 - 5 } & $R_{T, \text { heavy }}$ & 1.03 & 0.76 & 1.21 \\
\cline { 2 - 5 } & $R_{T, \text { light }}$ & 0.99 & 1.11 & 0.90 \\
\hline \multirow{3}{*}{2} & $\Delta[\%]$ & -0.62 & 8.51 & -6.87 \\
\cline { 2 - 5 } & $R_{T, \text { heavy }}$ & 1.02 & 0.76 & 1.20 \\
\cline { 2 - 5 } 3 & $R_{T, \text { light }}$ & 0.99 & 1.13 & 0.89 \\
\cline { 2 - 5 } & $\Delta[\%]$ & -1.40 & 7.51 & -7.51 \\
\cline { 2 - 5 } & $R_{T, \text { heavy }}$ & 1.04 & 0.78 & 1.23 \\
\cline { 2 - 5 } & $R_{T, \text { light }}$ & 0.98 & 1.11 & 0.89 \\
\hline
\end{tabular}


As presented in step 8 of algorithm in Section 2, the annual average levels $L_{d, \text { ref }}, L_{e, \text { ref }}, L_{n, \text { ref }}$ for day, evening and night rating time intervals at reference point now may be calculated using formula (6). And finally, the annual average levels $L_{d}, L_{e}, L_{n}$ for day, evening and night rating time intervals at receiver point of investigated living environment using formula (8) as well the desired composite annual level $L_{d e n}$ are being estimated, by applying the formula (1). All results were obtained separately for 3 measurement time intervals and are presented in Table 5.

In Fig. 7, as an example, the measured histogram of first time interval and corresponding extrapolated histogram for evening rating time period are presented.

Table 5. Annual noise values estimated from measured results and calculated ones $(\mathrm{dB})$

\begin{tabular}{|c|c|c|c|c|c|}
\hline \multirow{2}{*}{$\begin{array}{c}\text { Interval } \\
\text { No. }\end{array}$} & \multirow[b]{2}{*}{ Parameter } & \multicolumn{3}{|c|}{ Rating time period } & \multirow[b]{2}{*}{$L_{\text {den }}$} \\
\hline & & $\begin{array}{c}\text { Day } \\
(12 \mathrm{~h})\end{array}$ & $\begin{array}{c}\text { Evening } \\
(4 \mathrm{~h})\end{array}$ & $\begin{array}{l}\text { Night } \\
(8 \mathrm{~h})\end{array}$ & \\
\hline \multirow{2}{*}{1} & $L_{\text {Aeq,T,ref }}(1$ point $)$ & 77.1 & 74.2 & 69.4 & 78.4 \\
\hline & $L_{\text {Aeq,T,rec }}(2$ point $)$ & 68.6 & 65.7 & 60.9 & 69.9 \\
\hline \multirow{2}{*}{2} & $L_{\text {Aeq,T,ref }}(1$ point $)$ & 76.9 & 74.0 & 69.1 & 78.1 \\
\hline & $L_{\text {Aeq,T,rec }}(2$ point $)$ & 68.2 & 65.3 & 60.4 & 69.4 \\
\hline \multirow{2}{*}{3} & $L_{\text {Aeq,T,ref }}(1$ point $)$ & 76.6 & 73.8 & 68.8 & 77.8 \\
\hline & $L_{\text {Aeq,T,rec }}(2$ point $)$ & 68.3 & 65.5 & 60.5 & 69.5 \\
\hline
\end{tabular}

From the final results presented in Table 5, it may be concluded that the desired composite annual level $L_{d e n}$ assessed for considered point in living environment (bolded values) has a standard deviation of $0.27 \mathrm{~dB}$, that shows a good repeatability of results and allows to hope that the expanded uncertainty of suggested method with $95 \%$ probability of tolerances is not exceeding $3 \mathrm{~dB}$ limit. Also, it is important to note that calculated data in reference point 1 annual $L_{d e n}$ value for considered road using the known NordTest method (Bendtsen 1999) show a $77.7 \mathrm{~dB}$ result that is in tolerance limits of measured results.

\section{Conclusions}

1) The research of this paper shows a possibility to perform the annual $L_{d e n}$ assessment by permanent measurements in representative short-term time interval (till $1 \mathrm{~h}$ ) in the living areas near (till $50 \mathrm{~m}$ ) suburban arterial roads for Lithuanian traffic flow conditions. The appropriate algorithm for $L_{d e n}$ assessment is suggested. Firstly, it is based on the checking for initial measured data to be a representative ones, which proposes that the number of heavy and light vehicle passing by must fulfil the measurement accuracy requirement of standard (LST ISO 1996-2:2008); the proportion of heavy and light vehicle must be similar to declared annual average proportion of these vehicle categories for the day time, when measurements are carried out; meteorological conditions must be stable and normal and road surface must be dry.

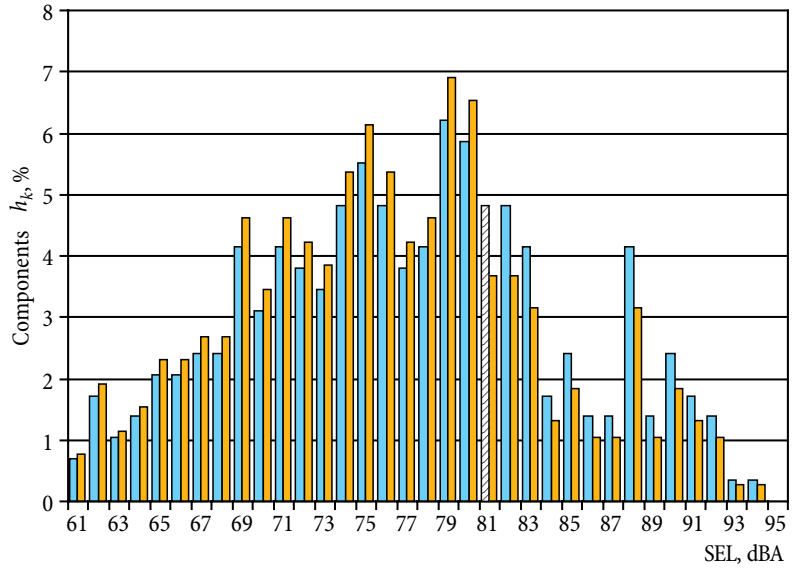

Fig. 7. Example of measured (blue columns) and extrapolated (yellow columns) histograms; dashed column (81 dBA) $-\mathrm{SEL}^{\star}$ value that separates light transport SEL's from the heavy ones

2) The measurement procedure allows to estimate the sound propagation correction by simultaneous sound levels acquisition on reference and receiver microphones. The correction due to road pavement characteristics (profile, type, exploitation time) is included automatically in the acquired sound levels.

3) The proposed algorithm contains the original extrapolation procedure that allows to adapt results obtained in representative time interval to the annual average rating time periods of day $(12 \mathrm{~h})$, evening $(4 \mathrm{~h})$ and night $(8 \mathrm{~h})$ for those to whom the $L_{d e n}$ value is assessed. Procedure is based on the statistical processing of SEL distribution histogram of all vehicles passing by events, being registered by the reference microphone.

4) The accomplished experimental measurements in considered living site in three separate measurement time intervals show that the standard deviation of repeatability of estimated $L_{d e n}$ values $(69.9 \mathrm{~dB}, 69.4 \mathrm{~dB}$ and $69.5 \mathrm{~dB}$ ) is $0.27 \mathrm{~dB}$. At the reference point obtained $L_{d e n}$ results $(78.4 \mathrm{~dB}, 78.1 \mathrm{~dB}$ and $77.8 \mathrm{~dB})$ are in limit of tolerances with the result of the wellknown NordTest calculation method of $77.7 \mathrm{~dB}$.

\section{References}

Bendtsen, H. 1999. The Nordic prediction method for road traffic noise, Science of The Total Environment 235(1-3): 331-338. http://dx.doi.org/10.1016/S0048-9697(99)00216-8

Cho, D. S.; Kim, J. H.; Choi, T. M.; Kim, B. H.; Manvell, D. 2004. Highway traffic noise prediction using method fully compliant with ISO 9613: comparison with measurements, Applied Acoustics 65(9): 883-892.

http://dx.doi.org/10.1016/j.apacoust.2004.03.004

Directive 2002/49/EC of the European Parliament and of the Council of 25 June 2002 Relating to the Assessment and Management of Environmental Noise. Available from Internet: http://eur-lex.europa.eu/LexUriServ/LexUriServ.do?ur $\mathrm{i}=\mathrm{OJ}: \mathrm{L}: 2002: 189: 0012: 0025: \mathrm{EN}: \mathrm{PDF}$

Gaja, E.; Gimenez, A.; Sancho, S.; Reig, A. 2003. Sampling techniques for the estimation of the annual equivalent 
noise level under urban traffic conditions, Applied Acoustics 64(1): 43-53. http://dx.doi.org/10.1016/S0003-682X(02)00050-6

Hamet, J.-F.; Besnard, F.; Doisy, S.; Lelong, J.; Le Duc, E. 2010. New vehicle noise emission for French traffic noise prediction, Applied Acoustics 71(9): 861-869. http://dx.doi.org/10.1016/j.apacoust.2010.05.003

Jagniatinskis, A.; Fiks, B. 2014. Assessment of environmental noise from long-term window microphone measurements, Applied Acoustics 76: 377-385.

http://dx.doi.org/10.1016/j.apacoust.2013.09.007

Jagniatinskis, A.; Fiks, B. 2012. Assessment of annual noise near exurbia arterial roads applying statistical processing of short term measurements, in The 9th European Conference on Noise Control, EURONOISE 2012: Proceedings, 10-13 June, 2012, Prague, Czech Republic, 1501-1506. (CD).

Jagniatinskis, A.; Fiks, B.; Mickaitis, M. 2011. Statistical assessment of environmental noise generated by road traffic, Transport 26(1): 96-105. http://dx.doi.org/10.3846/16484142.2011.568084

King, E. A.; Rice, H. J. 2009. The development of a practical framework for strategic noise mapping, Applied Acoustics 70(8): 1116-1127. http://dx.doi.org/10.1016/j.apacoust.2009.01.005

Lietuvos Respublikos triukšmo valdymo ìstatymas. $2004 \mathrm{~m}$. spalio 26 d. Nr. IX-2499, Vilnius (in Lithuanian).

LST ISO 1996-2:2008. Akustika. Aplinkos triukšmo aprašymas, matavimas ir ìvertinimas. 2 dalis. Aplinkos triukšmo lygiu nustatymas [Acoustics - Description, Measurement and Assessment of Environmental Noise - Part 2: Determination of Environmental Noise Levels].

Mato-Méndez, F. J.; Sobreira-Seoane, M. A. 2011. Blind separation to improve classification of traffic noise, Applied Acoustics 72(8): 590-598.

http://dx.doi.org/10.1016/j.apacoust.2011.02.006

Ng, C. H.; Tang, S. K. 2008. On monitoring community noise using arbitrarily chosen measurement periods, Applied Acoustics 69(7): 649-661.

http://dx.doi.org/10.1016/j.apacoust.2007.01.003

Pamanikabud, P.; Tansatcha, M. 2003. Geographical information system for traffic noise analysis and forecasting with the appearance of barriers, Environmental Modelling \& Software 18(10): 959-973. http://dx.doi.org/10.1016/S1364-8152(03)00097-5

Steele, C. 2001. A critical review of some traffic noise prediction models, Applied Acoustics 62(3): 271-287.

http://dx.doi.org/10.1016/S0003-682X(00)00030-X 